\title{
RETRATOS PARA A UNESCO DA RESERVA DA BIOSFERA DO CERRADO - RESBIO GOYAZ: SUAS PAISAGENS CULTURAIS E IDENTIDADES TERRITORIAIS
}

\author{
PORTRAITS FOR UNESCO FROM GOYAZ CERRADO BIOSPHERE RESERVE: \\ ITS CULTURAL LANDSCAPES AND TERRITORIAL IDENTITIES
}

\section{PORTRAITS POUR L'UNESCO DE LA RESERVE DE BIOSPHERE GOYAZ - CERRADO: PAYSAGES CULTURELS ET IDENTITÉS TERRITORIALES}

\author{
Maria Geralda Almeida - Universidade Federal de Goiás - Goiânia - Goiás - Brasil \\ mgdealmeida10@gmail.com
}

\begin{abstract}
Resumo
Neste artigo preocupa-se em averiguar paisagens culturais e identidades territoriais que se vinculam às apropriações diversas dos atores e sujeitos na Reserva da Biosfera do Cerrado. A paisagem cultural é concreta, material e factualmente percebida pelos sujeitos e assimilada afetiva e culturalmente pelos homens. Simultaneamente, buscaram-se as identidades territoriais mediante a aplicação de algumas tipologias. $\mathrm{Na}$ investigação recorreu-se aos procedimentos qualitativos e quantitativos e à cartografia. Conclui-se que a Reserva da Biosfera do Cerrado - Resbio Goyaz -, apesar de seus 25 anos, carece de vontade política para sua implementação. As paisagens culturais são dinâmicas e sinalizam a precarização da Resbio Goyaz, diferentemente do que concebe a Unesco. E as identidades territoriais são reveladoras de conflitos e disputas empobrecedoras do valor da Resbio para a conservação ambiental do Cerrado e a sustentabilidade.

Palavras-chave: Políticas ambientais. Uso da terra. Agronegócio. Populações tradicionais. Fragilidade ambiental.
\end{abstract}

\section{Abstract}

At Goiás state, the Reserve occupies the most conserved Cerrado's space and is of great importance for biodiversity. This essay centers upon the cultural landscapes and territorial identities that attach spatial marks by the mans of the appropriation effected by diverse actors and subjects present at Goyaz Cerrado Biosphere Reserve. Cultural landscape is materially concrete and factually perceived by subjects and, in this sense, this object is affectively and culturally assimilated by humans. Simultaneously, territorial identities were searched by the use of typologies. In the investigation, qualitative and quantitative proceedings were used alongside cartography. It is concluded that Goyáz Cerrado Biosphere Reserve, 25 years after its creation, still demands proceedings for its implementation. These cultural landscapes are dynamic and their historicity indicates the precarization of the Biosphere Reserve, contrarily to what Unesco conceived; and, territorial identities are revealing of conflicts and disputes that lowers the values of Resbio for environmental conservation and sustainability.

Keywords: Environmental policies. Land use. Agribusiness. Traditional populations. Environmental fragility.

\section{Résumé}

Dans cet article le but est d'étudier les payages culturels et les identités territoriales vinculés aux apropriations diversifiées des acteurs et sujets de la réserve de la biosphere Goyaz-Cerrado. Le paysage culturel est concrect, materiel et factuelment perçu par sujets et en plus assimilé par leurs sentiments et culture par les hommes. Au même temps les identités territoriales avec quelques tipologies. I'investigation par les quêtes quantitatifs, qualitatives et cartographie a permis quelques conclusions.Malgré les 25 ans d'existence il manqué la volonté politique pour mettre en place les buts de l'Unesco. Les paysages culturels dynamiques signalent la 
precarization de la Réserve au contraire du conçu par I'Unesco. Les identités territoriales signalent conflits et bagarres appauvrissants de la valeur de la Resbio en tant que moyen pour la conservation environnementale de savanne et la sustentabilité.

Mots-clé: Politiques environnementales. Utilisation du sol. Agro-alimentaire. Populations traditionnelles. Fragilité environnementale.

\section{Apresentação}

O Cerrado, desde a década de 1990, é considerado não somente uma terra para agricultura de exportação, mas também, com a assinatura da Convenção sobre Diversidade Biológica (CDB), o bioma de um novo paradigma, o do desenvolvimento sustentável. E, nessa mesma década, a Unesco identifica no Cerrado um ambiente singular, pela biodiversidade representativa, reconhecida mundialmente pelo seu valor e necessária conservação ambiental, recomendando-a como uma Reserva da Biosfera (UNESCO, 2008).

Os planejadores de políticas têm ignorado o papel importante do Cerrado como emissor de gases de efeito estufa, provocados pelo seu alto índice de desmatamento. Foi o que demonstraram Katia Abreu, ministra da Agricultura no período de $1^{\circ}$ de janeiro de 2015 a 12 de maio de 2016, e os membros da bancada ruralista, ao estimularem a expansão agrícola no Cerrado. Ressalta-se nesse âmbito a área denominada Matopiba, na fronteira entre o Maranhão, Tocantins, Piauí e Bahia, que, embora considerada como Reserva da Biosfera do Cerrado, teve um acentuado crescimento do desmatamento, tornando-a a maior produtora de soja nesse tipo de biosfera.

Pode-se interpretar essa meta como uma licença para desmatar o Cerrado ao máximo do que é permitido pelo Código Florestal (ou seja, $80 \%$ da propriedade). Vale assinalar que $400.000 \mathrm{~km}^{2}$ ficariam, assim, susceptíveis a serem desmatados legalmente, visto que $110.000 \mathrm{~km}^{2}$ já foram reconhecidos no Cerrado como propícios ao cultivo de soja.

Por conseguinte, o enfoque deste artigo incidirá, sobretudo, no contexto da Reserva da Biosfera do Cerrado - Resbio Goyaz -, para verificar suas condições mais recentes. O objetivo é atentar para a diversidade paisagística que mantém um percentual significativo de Cerrado como áreas protegidas, embora coexistindo com áreas de grãos e outros empreendimentos que se espalham no interior da área desmatada da própria Reserva da Biosfera do Cerrado. Exceções existem onde as 
condições de solo e morfológicas retardaram a ocupação com o agronegócio e permitiram que uma população tradicional, com destaque para os Quilombolas, conhecidos localmente como Kalunga, ali constituísse um território de povos do Cerrado (Almeida, 2005, 2010).

A Reserva de Biosfera do Cerrado - Resbio Goyaz - veio ressaltar o propósito comunitário de conservar o Cerrado do norte e nordeste goiano e também suas populações. Todavia, a expansão agressiva da pecuária e da sojicultura é veloz, o que leva à estratégia governamental de criação de um mosaico de Unidades de Conservação - UCs -, uma vez que a produção de fragmentos de Cerrado restringe o total desmatamento da mais conservada área do Cerrado goiano. Aparentemente, as diversas UCs são uma proteção para a Reserva da Biosfera.

Portanto, preocupa-se em averiguar as existências e como as identidades territoriais e as paisagens culturais marcam a Reserva da Biosfera do Cerrado. As paisagens culturais que interessam aqui são uma marca dos diversos fragmentos paisagísticos no seio da Reserva da Biosfera do Cerrado.

Para as análises e resultados respaldou-se em diversas entrevistas semiestruturadas, realizadas com cinco comunidades de Quilombolas, assentados de dezesseis assentamentos nos municípios de Alvorada, Buritinópolis, Cavalcanti, Colinas do Sul, Damianópolis, Iaciara, Flores de Goiás, Mambaí, Nova Roma, Posse, Teresina de Goiás, no período de 2013 a 2018. Também se baseou em entrevistas com as lideranças de associações representantes de empresas que fornecem assistência técnica nos assentamentos como Senar e Coopera-DR, técnicos de órgãos federais (Incra e ICMBio Chico Mendes, em Mambaí), do Estado (Emater, em Posse) e municipais (secretários da Agricultura e do Meio Ambiente). Com apoio em dados de Censos Agropecuários do IBGE (2000 a 2010), foram elaborados cartogramas sobre o uso da terra.

A discussão baseada nessas informações espalha-se pelos três tópicos: no primeiro, mediante uma descrição geral, aborda-se a complexidade presente na Reserva da Biosfera do Cerrado; no segundo, por meio de suas paisagens culturais, aprofunda-se a discussão acerca dessa Reserva; no último tópico, delineiam-se as identidades territoriais existentes nela. 


\section{Reserva da Biosfera do Cerrado - Resbio Goyaz}

Reservas de Biosfera são definidas como "áreas de ambiente, representativas, reconhecidas mundialmente pelo seu valor para a conservação ambiental e para o provimento de conhecimento científico, da experiência e dos valores humanos com vistas a promover o desenvolvimento sustentável”, nos termos da Unesco (2008). No estado de Goiás, a Reserva da Biosfera do Cerrado encontra-se em uma das regiões de maior conservação de Cerrado e de grande importância para a biodiversidade. Corresponde a 13,45\% da área goiana e abriga 7,84\% da população total do estado, com 470.574 mil habitantes (IBGE, 2010). Se incluído o DF, a Reserva da Biosfera do Cerrado torna-se mais expressiva em população.

Esse foi um dos motivos que levaram a sua inclusão, pela Unesco, ao Programa o Homem e a Biosfera, tornando-se parte da Reserva da Biosfera $^{2}$ do Cerrado desde 1994.

Localizada no norte e nordeste do estado de Goiás (Centro-Oestre do Brasil), a Reserva da Biosfera do Cerrado possui uma área territorial de $54.392 \mathrm{~km}^{2}$, considerados como zona de transição (Figura 1). Importante assinalar que a Reserva da Biosfera do Cerrado ainda compreende a reserva indígena Avá-Canoeiro, a noroeste da região, e o Sítio Histórico e Patrimônio Cultural da comunidade tradicional de Quilombolas Kalunga, no norte da região.

O Ministério do Meio Ambiente (MMA) recentemente propôs uma revisão e uma atualização dos Limites da Reserva da Biosfera do Cerrado, que foram aprovadas no dia 18 de setembro de 2018, em Brasília, DF, o que consideramos como a quarta fase de sua delimitação. O novo desenho priorizou a conectividade do Cerrado com os biomas Caatinga, Mata Atlântica e Pantanal e abrange cerca de 74 milhões de hectares, incluindo os estados da Bahia, Minas Gerais, Mato Grosso, Paraná e São Paulo e juntando-se ao Distrito Federal, Goiás, Piauí, Tocantins e Maranhão, que já compunham a Reserva da Biosfera. O documento técnico, com esse propósito, foi submetido à avaliação e teve a aprovação da Unesco em 2019. 
Figura 1 - Situação da Reserva da Biosfera do Cerrado - Resbio Goyaz -, com destaque para as diversas Unidades de Conservação, Áreas de Proteção Ambiental (APA) e Terras protegidas

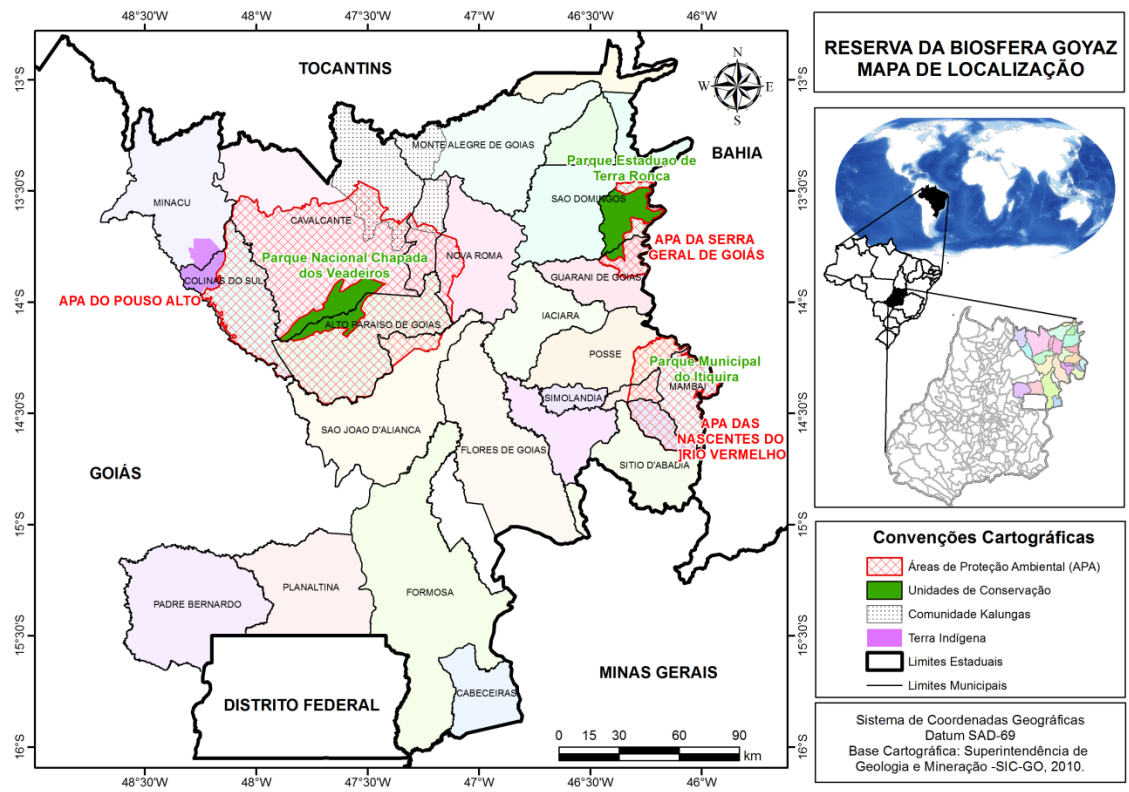

Nascimento et al. (2016) concluem que a região compreendida pela Reserva da Biosfera do Cerrado - Resbio Goyaz - ainda possui 64\% de sua área revestida por cobertura vegetal natural, ao passo que as áreas ocupadas por atividades de agricultura, pastagem e área urbana representam cerca de $35,5 \%$ de sua área.

A Reserva ainda apresenta rica rede de drenagem, com maior densidade na porção sul e volume expressivo de corpos hídricos na porção noroeste - representados pela Lagoa de Cana Brava e de Serra da Mesa, situadas nos municípios do norte Goiano, ambas utilizadas para geração de energia elétrica. As paisagens são predominantemente da natureza, com exceção naquela da drenagem, em que há maior presença das transformações resultantes das relações sociais com recursos hídricos. Essas usinas elétricas são signos atípicos (Copeta, 2009) da modernidade, que conflitam com as paisagens valorizadas como patrimônio local. 
Figura 2 - Unidades de fragilidade ambiental da Reserva da Biosfera do Cerrado - Resbio Goyaz

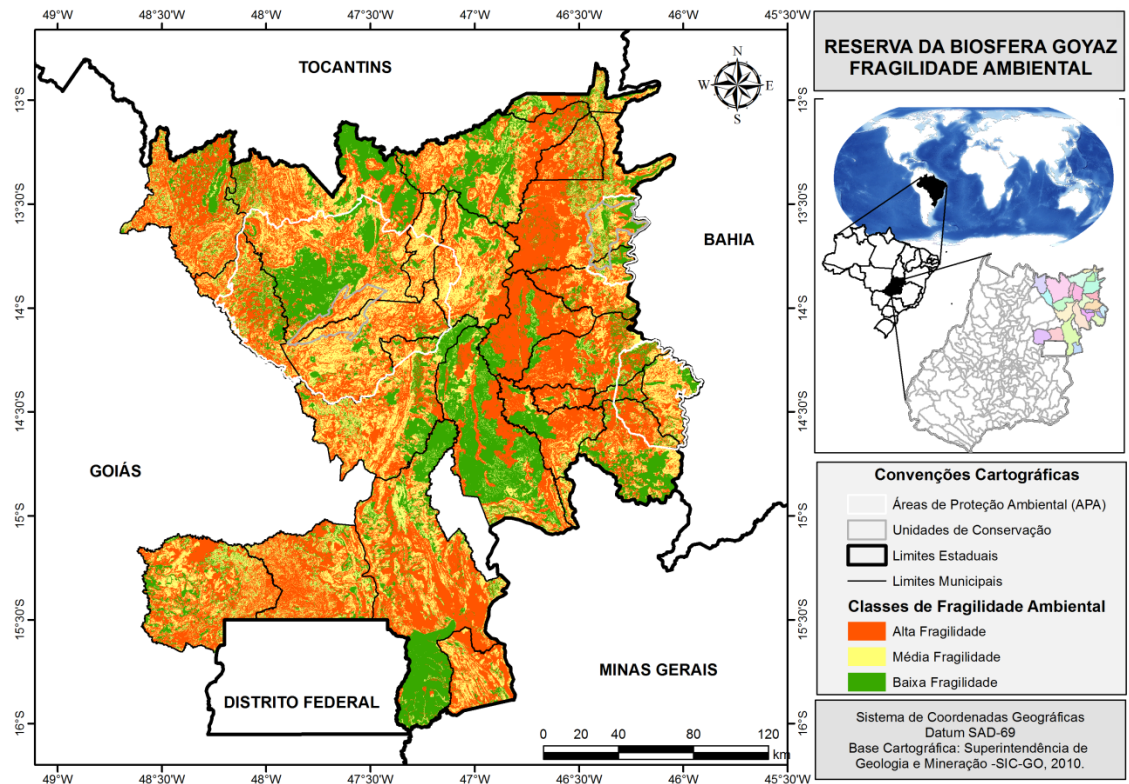

Da análise integrada da resistência dos componentes naturais em face das intervenções humanas, a Figura 2 indica as unidades de alta, média e baixa fragilidade ambiental da Reserva da Biosfera do Cerrado - Resbio Goyaz. Em geral, são paisagens precarizadas marcando o território da Reserva. Conclui-se que as análises paisagísticas não podem prescindir de uma breve descrição ao se buscar a interpretação dos signos de antropização histórica. A descrição evidencia as constantes, os signos construídos e também a qualidade da paisagem por meio da combinação das funções primárias e as funções secundárias.

As áreas de baixa fragilidade se encontram em manchas esparsas vistas na porção sul, central e ao norte da Reserva da Biosfera, correspondendo a trechos elevados do Planalto Central. Elas também atingem áreas de chapadas e patamares na porção oeste da Reserva e de planaltos na porção central e porções fragmentadas no noroeste, havendo um considerável fragmento inserido na APA do Pouso Alto. Por sua vez, as áreas de alta fragilidade ambiental se concentram na porção sul, numa faixa longitudinal no nordeste, correspondente ao Vão do Paranã, 
e em porções fragmentadas no noroeste, por conta da pecuária e das monoculturas de arroz, milho e eucaliptos.

Importante destacar a pressão exercida pelas unidades de alta fragilidade no entorno das Unidades de Conservação e suas respectivas Áreas de Proteção Ambiental. Porém, ainda existe considerável área de baixa fragilidade, principalmente nas APAs de Pouso Alto e da Serra Geral de Goiás. Ademais, mesmo dentro dessas áreas ocorrem unidades de média e alta fragilidade, sem que o governo coloque em prática as políticas que existem na Reserva da Biosfera do Cerrado. Enfim, os signos da degradação se manifestam de distintas maneiras e por meio de processos complexos e articulados, sem estudos da repercussão efetiva no território. Mesmo assim, procurou-se neste artigo esboçar, em caráter preliminar, uma breve leitura.

A caracterização geoambiental e o mapeamento da fragilidade ambiental propiciam importantes insumos à gestão, ao monitoramento e ao manejo da Reserva da Biosfera do Cerrado - Resbio Goyaz. A sua existência como unidade especial, reconhecida mundialmente pelo seu valor para a proteção ambiental e para o provimento de conhecimento científico, torná-la-ia objeto de atenção e de políticas especiais para atender às expectativas da Unesco e aos interesses de uma política conservadora ambientalista.

Doyle (2009) lembra que as Resbio não são unidades de conservação. Elas fazem parte dos espaços territoriais especialmente protegidos (ETEP), os quais incluem as UCs. Logo, elas não têm a exigência de elaboração de um plano de manejo para orientar a sua gestão. Entretanto, todas as seis Resbio da Rede Brasileira devem instituir seu Conselho Deliberativo como instrumento de gestão. O Conselho tem a atribuição de aprovar e coordenar a estrutura do sistema de gestão da Reserva, bem como elaborar os planos de ação e propor projetos estratégicos para a consolidação da área delimitada.

Contudo, somente em 2018, pela Portaria $\mathrm{n}^{\circ} 275$, de 5 de julho, o Ministério do Meio Ambiente (Brasil, 2018) cria e define a composição do Conselho Deliberativo da Reserva da Biosfera do Cerrado - Resbio Goyaz. Ou seja, isso só ocorreu vinte e cinco anos após ter sido criada, período em que foi célere a expansão da pecuária e agronegócio no Cerrado, contrariando a conservação da biodiversidade e o uso da Reserva, que se respaldam no discurso do desenvolvimento sustentável. 
Embora instituído, as mudanças ocorridas no cenário político, após as eleições em 2018 para presidente da República e governador do Estado, respingaram no Conselho Deliberativo. Seus membros foram, em sua maioria, exonerados e, passados três meses, o Conselho continua sem renovação. Ademais, os vinte e cinco anos de existência não foram suficientes para dar visibilidade à Reserva da Biosfera do Cerrado. Os gestores municipais e lideranças comunitárias ignoram o que seja de fato uma Resbio. Efetivamente a intenção da Unesco em proteger o bioma como patrimônio, com a implantação e gestão da Reserva da Biosfera do Cerrado, ainda permanece como uma proposta inócua e desvalorizada.

\section{0 território da Reserva da Biosfera do Cerrado - Resbio Goyaz - e seus territórios culturais}

De modo geral, os objetivos das políticas desenvolvimentistas e das políticas ambientalistas são amplos e contraditórios. Eles são conflitivos ao permitir a coexistência de diferentes padrões de uso dos solos e da biodiversidade e ao mesmo tempo estabelecer os efeitos de cada um sobre o outro. As políticas ditas socioambientalistas procuram, grosso modo, controlar as atividades do agronegócio, criar novas áreas protegidas e facilitar a implementação das ferramentas de proteção e valoração dos conhecimentos tradicionais sobre biodiversidade; ao mesmo tempo, buscam promover ações de desenvolvimento e valorização social. Tais políticas têm implicações no que diz respeito às paisagens culturais e às identidades, como se tratará a seguir.

Por que as paisagens culturais? Cosgrove (1998) dizia ser pela paisagem que se pode ter uma nova maneira de ver o mundo, como uma criação racionalmente ordenada, cuja estrutura e mecanismos são acessíveis à mente humana. Entender e interpretar a paisagem implica, pois, uma visão de mundo de quem o faz. Paisagem, na concepção da geografia cultural, diz respeito à nossa posição na natureza, de que sua elaboração se dá pela percepção e pela razão humana e que ela sempre esteve ligada com a cultura. Sauer ([1925]1998) afirmava que, na formação cultural, a cultura é o agente, a paisagem natural é o meio e a paisagem cultural é o resultado.

A paisagem cultural é um objeto concreto, material, físico e factual percebido pelos sujeitos por meio dos cinco sentidos. Dessa forma, trata-se 
de objeto que é assimilado afetiva e culturalmente pelos homens. A paisagem cultural é, assim, a imagem sensorial, afetiva, simbólica e material dos territórios na opinião de Beringuier (1991). Essa definição contempla os conceitos de paisagem visual, paisagem valorizada e paisagem percebida. Além disso, as paisagens revelam a historicidade das relações entre a sociedade e a natureza e a concepção de mundo dos homens que as modelaram.

No dizer de Santos (1997, p. 83), a paisagem é "[...]transtemporal, juntando objetos presentes e passados. É uma construção transversal”. Dessas configurações, a lógica econômica participa, mas a história e a memória contam com todo o seu peso. As paisagens emergem segundo as experiências e as percepções de cada indivíduo. Todas essas leituras revelam a paisagem cultural em sua dimensão sensorial, histórica, cultural e simbólica, porém refletindo a visão de mundo de cada sujeito. Daí o cuidado ao referir-se às paisagens culturais (Almeida; Vargas; Mendes, 2011).

As representações cartográficas presentes neste artigo representam a natureza, formas de uso e atividades agrícolas e ambientais na sua dinâmica temporal. Se a lógica econômica é a dimensão escolhida, pode-se afirmar que a paisagem testemunha a aventura do homem na superfície da terra, e qualquer marca por ele introduzida significa um diferente valor cultural. Técnicas, crenças ideológicas, visão de mundo perpassam cada paisagem, por isso as paisagens possuem significados simbólicos. A diversidade de paisagens na Reserva da Biosfera do Cerrado - Resbio Goyaz - distingue os rebanhos, as lavouras temporárias, e os municípios da extensão da soja delimitam o espaço do poder, também carregados de ideologias. São paisagens reconhecidas como testemunhas da criatividade, da diversidade sociocultural, da exclusão social, do domínio do capital, dos cenários de vida, e tornam-se objetos de interesse de políticas nacionais e internacionais. As paisagens culturais transformam-se em objetos de políticas valorativas, conservacionistas e, ainda, de atrações turísticas.

Tanto a paisagem quanto o território são dimensões marcadas por elementos patrimoniais, signos da trajetória da sociedade que ativam a memória e situam os grupos definindo suas identidades. Tais dimensões são produtos e, ao mesmo tempo, produtoras da natureza social e cultural das sociedades. Com isso, não se afirma que as ações dos homens sejam determinadas pela moldura material do meio ambiente, mas ressaltam-se 
as imbricações que existem e permeiam as paisagens culturais. Elas refletem a superposição de poderes e de símbolos dos homens (GANDY, 2004).

Se se observar a dinâmica paisagística nesse período de existência da Reserva da Biosfera do Cerrado, as intensas marcas das atividades que exploraram o Cerrado sobressaem. É o caso, por exemplo, das pastagens. A análise criteriosa feita por Nascimento e Silva (2014) conclui que as áreas ocupadas por pastagens nos municípios compreendidos pela Resbio Goyaz apresentaram uma redução de 8,7\% entre 1995 e 2006, considerando a perda de 251 mil hectares no período observado. Contudo, essa utilização da terra continua sendo bem presente sobre o território, correspondendo a 37,6\% da área da Resbio Goyaz em 2006. A dinâmica existente entre 1995 e 2006 indica que os municípios do sul e leste da área dessa Reserva mostraram tendência de diminuição de áreas de pastagens, ao passo que alguns municípios do sudeste, centro e noroeste mostraram aumento de pastagens.

Apesar da redução, Formosa continua sendo o município com maior área de pastagens (266.206 ha), seguido por Flores de Goiás (220.498 ha) e Cavalcante (201.587 ha). São paisagens que resultam do poder econômico, da tecnologia e ainda da condição sociocultural de seus atores e sujeitos. Grande destaque deve se atribuir à substituição das áreas de pastagens por áreas de cultivo da milho, soja e eucaliptos vista nos municípios concentrados no entorno do Distrito Federal. Tal fato pode sugerir a influência da capital federal à dinâmica do uso das terras nos municípios vizinhos, assim como naqueles situados no nordeste da Resbio Goyaz, onde se localiza o Vão do Paranã, uma depressão que, em sentido leste, na divisa com a Bahia, bruscamente apresenta um aumento da altitude ao encontro das Chapadas do Rio São Francisco, fato este que dificulta a criação de rebanhos.

Contudo, uma análise de dados recentes revela uma tendência de diminuição da área de pastagens para implantação de lavouras não apenas 
na Resbio, mas também no estado de Goiás, conforme visto pelos dados apresentados na Tabela 1. Nela demonstra-se que entre 1995 e 2006 houve um decréscimo de 3.879.997 hectares de áreas de pastagens; que no período entre 2006 e 2017 esse decréscimo foi de menos 466.052 hectares; que entre 1995 e 2006 houve um aumento de 1.415.726 hectares de áreas revestidas por lavouras, dinâmica que permanece entre 2006 e 2017. Apesar da conversão, as áreas de pastagens continuam sendo bastante superiores àquelas de lavouras no estado de Goiás.

Tabela 1 - Utilização das terras por lavouras e pastagens no Estado de Goiás (em hectares)

\begin{tabular}{|l|l|l|l|l|l|}
\hline & 1995 & 2006 & 2017 & Dinâmica 1995-2006 & Dinâmica 2006-2017 \\
\hline Lavouras & 2.174 .853 & 3.590 .579 & 4.913 .602 & 1.415 .726 & 1.323 .023 \\
\hline Pastagens & 19.404 .696 & 15.524 .699 & 15.058 .647 & -3.879 .997 & -466.052 \\
\hline
\end{tabular}

Fonte: Censo Agropecuário do IBGE de 1995, 2006 e 2017.

Com relação ao rebanho bovino (Figura 3), houve um aumento de 104.019 cabeças de gado entre 2004 e 2010 em toda região compreendida pela Resbio Goyaz. Tanto em 2004 quanto em 2010 nota-se que os municípios com maior rebanho concentraram-se ao longo das rodovias BR-020 e GO-110, uma malha viária facilitadora do escoamento da produção leiteira e carne.

Com relação ao ano de 2010, o que se vê é o aumento do rebanho de bovino em quase todos os municípios da Resbio Goyaz. O aumento desse rebanho, apesar da diminuição da área ocupada por pastagens, sugere que a criação de bovinos realiza-se de forma mais intensiva, como reflexo do predomínio da prática para exploração capitalista. A paisagem da pecuária é de tradicionais pastagens conflitando com a vegetação de cerrado e, mais recentemente, a pecuária ganhou técnicas modernas, selecionou mais a raça para o corte e usa a tecnologia. Porém, as vastas pastagens marcam as paisagens na Reserva da Biosfera. 
Figura 3 - Rebanho bovino presente na Reserva da Biosfera Goyaz

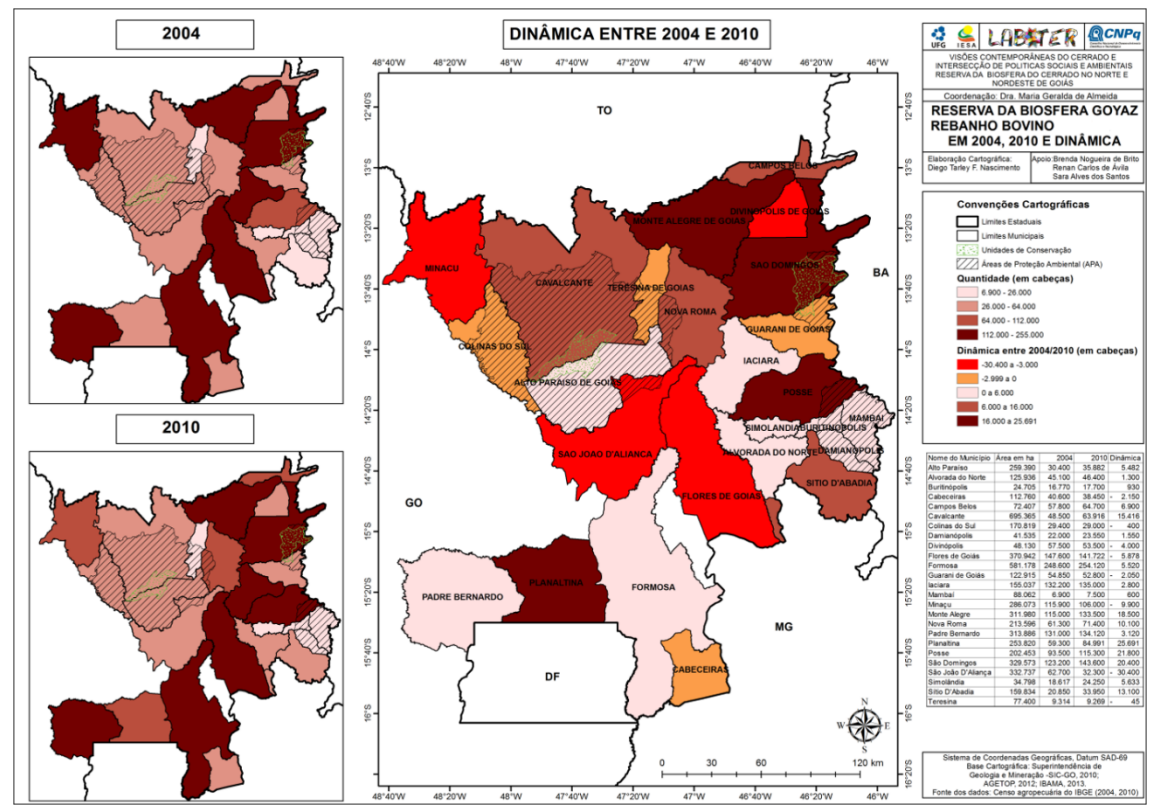

Fonte dos dados: Censo agropecuário do IBGE (2004 e 2010).

Mesmo assim, em análise da produção agrícola das principais culturas na região, evidenciam-se diferentes padrões e dinâmicas. Por exemplo, a produção de arroz e a de cana-de-açúcar se concentram nos municípios localizados ao norte e nordeste da Reserva da Biosfera do Cerrado, ao passo que a produção de milho e a de soja se concentram naqueles municípios situados na região sul. Isso confirma um aspecto já assinalado: a conversão das áreas de pastagens para atividade agrícola nos municípios ao sul da Reserva ocorre para a implantação dessas duas últimas culturas. Paisagens distintas são reelaboradas e estão em progressão no ambiente, na economia e na cultura daqueles que habitam aqueles territórios. 
No que se refere à lavoura temporária, na dinâmica entre 2004 e 2010 os municípios de São João da Aliança e Padre Bernado são aqueles que apresentaram as maiores elevações das áreas ocupadas por lavouras temporárias, com incremento de 13.117 e 8.995 hectares, respectivamente. Alguns municípios concentrados no nordeste apresentaram recuo de áreas de lavouras temporárias.

Vale notar que justamente os municípios situados ao sul da Resbio Goyaz foram aqueles que apresentaram aumento das áreas de lavouras permantes e, também, a diminuição das áreas de pastagem. Tal dinâmica, como já referido, corrobora a conversão de áreas pastoris para uso de lavouras predominantes do agronegócio. O município de Formosa destaca-se pela presença de silos ao longo da BR-020, nacionais e estrangeiros, como o Syngenta Seeds, Cereais Sul, Supply Chain Armazens Gerais Ltda., o que reforça e complementa as atividades de produção para um mercado exportador.

No que diz respeito à soja, um fenômeno na produção agrícola brasileira entre as lideranças no mercado mundial, na Reserva da Biosfera do Cerrado nove municípios responderem por essa produção agrícola (Figura 4). Salienta-se que foi a cultura que apresentou maior aumento entre 2004 e 2010. Nos dois períodos analisados houve um incremento de 754.526 toneladas de sua produção. Pode-se concluir que há concentração, especialização e intensificação da soja na Reserva da Biosfera Goyaz do Cerrado até na área de conservação da APA de Pouso Alto, com forte presença no município de Alto Paraíso, cujas culturas tocam as franjas do Parque Nacional da Chapada dos Veadeiros. 
Figura 4 - Produção de Soja em 2004, 2010: Reserva da Biosfera do Cerrado - Resbio Goyaz
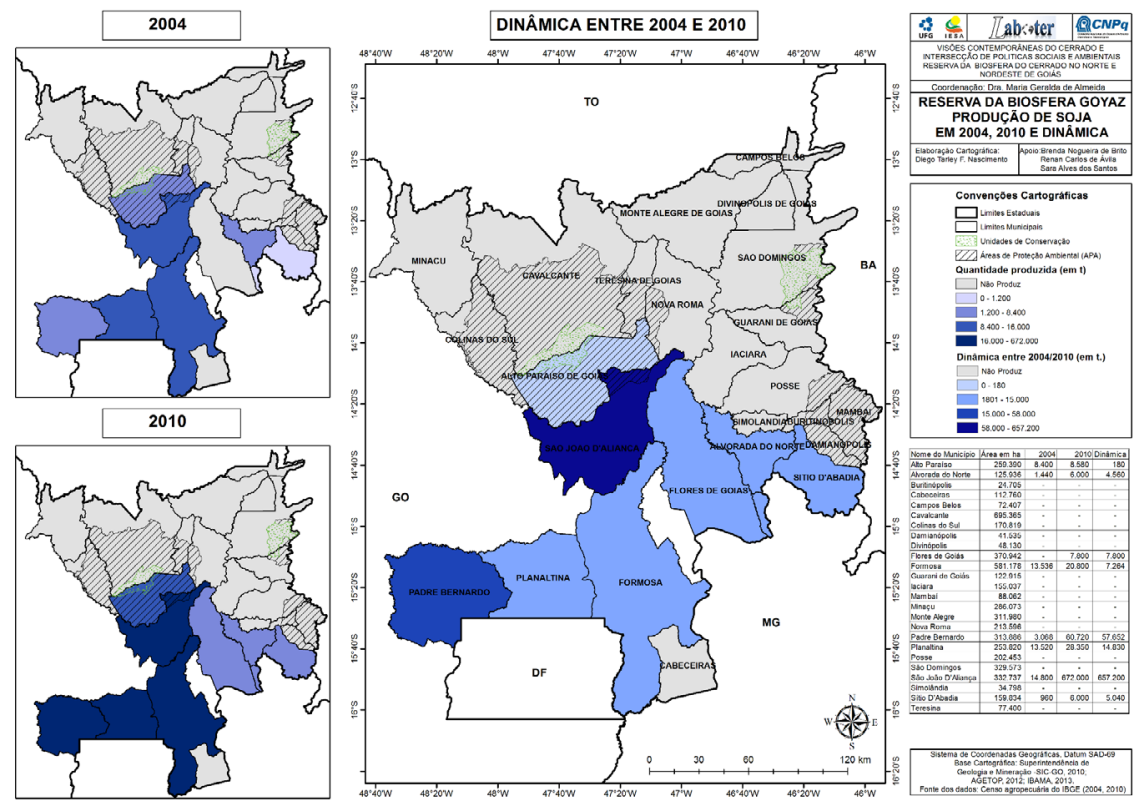

Identidades territoriais

Como já afirmado, paisagens também são consideradas como categoria de apreensão das forças tencionais na Resbio Goyaz. Elas possibilitam, assim, fazer uma análise do território para apreender a identidade. Identidade significa buscar na diferença o principium individuationis.

Para fazer um retrato da Resgio Goyaz, procuraram-se as pistas para identificar as identidades territoriais em suas variações considerando a identificação das "constantes" que constituem a estrutura e o núcleo da identidade. A primeira figura, que representa o território e diversas paisagens nos quais se encontram os sujeitos e agem os diversos atores, auxilia na compreensão da diversidade paisagística e territorial.

Os estudos feitos na Resbio Goyaz permitiram considerar que a identidade se entende como categoria descritiva do território, como leitura alternativa, que pode encontrar sua utilidade. Copeta (2009), com base em 
Paba (1998), aponta as múltiplas identidades pela revelação da diferença: diferença entre indivíduo e indivíduo, entre lugar e lugar, mundo e mundo.

Então, trata-se de diferenciação na escala horizontal entre identidade e identidade, e diferenciação interna e vertical também. Identidade como resíduo, fundamento ontológico ou bem como limite, ponto da aproximação, horizonte e objetivo. Nesse sentido, com base em Copeta (2009) pode-se entender a diferença entre assentados e Quilombolas; entre o lugar de cerradeiros e o lugar de pecuaristas; a diferença no mundo da Resbio Goyaz da Unesco e o mundo da Resbio Goyaz dos empresários da soja e das políticas governamentais. São as múltiplas identidades com sujeitos e atores no mesmo território. Conclui-se que se refere às identidades territoriais que "são dinâmicas e representam tempo, visão de mundo e como se veem os atores sociais em um dado momento econômico e político", como afirma Almeida (2012, p. 161).

Além disso, neste estudo, considerou-se ainda a tipologia proposta por Bassand (apud ALMEIDA, 2008, 2012), que a elaborou conforme o grau de pertencimento ou de identidade dos habitantes de determinado território. A tipologia é essencial para definir o nível de consciência socioespacial. Para esse autor, existem os apáticos e os resignados; os migrantes potenciais; os modernizadores; os tradicionalistas e os regionalistas.

No território Resbio Goyaz, essas identidades foram identificadas em grandezas diferenciadas: as populações tradicionais formadas por Quilombolas, os assentados em Projetos de Assentamentos da Reforma Agrária e os pequenos posseiros como tradicionalistas. Essas populações são dotadas de uma identidade histórica e que reivindicam um projeto territorial consistente para assegurarem suas atividades na terra da qual dependem para sua existência.

Importante lembrar que a sociedade brasileira desprezou os conhecimentos de vários grupos tradicionais, como os índios e os povos cerradeiros. "Os saberes locais, que constituem um patrimônio, há muito tempo desqualificados pela modernização agrícola, estão em regressão, por estarem enfraquecidos, uma vez que não são transmitidos, conforme afirmam Pinton e Aubertin (2007, p. 20). Contudo, as populações que permaneceram nas áreas remanescentes do bioma Cerrado vêm delineando suas configurações e funções de vida entre os significados tradicionais e valores modernos. Elas persistem na utilização de recursos naturais, 
sobretudo para assegurar a sua sobrevivência dificultada pela redução da área do Cerrado, em razão dos desmatamentos frequentes, da construção de barragens e da implantação de uma moderna agricultura. Há, todavia, evidências de recomposição das identidades ligadas à valorização do "tradicional", como a comercialização dos frutos do Cerrado mangaba (Hancornia speciosa), buriti (Mauritia flexuosa) e pequi (Caryocar brasiliense).

Duas outras identidades territoriais ainda estão presentes na Reserva da Biosfera: os migrantes ocasionais e os modernistas. Os primeiros dizem respeito a parcela considerável de homens assentados nos municípios fronteiriços com a Bahia, que migram, nos períodos críticos, para trabalharem nas fazendas do agronegócio no Oeste baiano. Em suas propriedades, a terra é pouco explorada e são as mulheres e os filhos que buscam nela produzir alguns alimentos para o uso diário. O trabalho valorizado, gerador de renda, é na condição de diarista ou assalariado mensal nas empresas de soja, milho, algodão e às vezes feijão.

Na Reserva da Biosfera desde a década de 2000 emergem na paisagem os signos atípicos. Estes dizem respeito a uma variável ou mais variáveis da identidade que têm um impacto negativo para a conservação da Reserva da Biosfera. São cultivos modernos do agronegócio, usando maquinário e pivôs de irrigação para a produção de grãos; outros espaços para as pastagens com criação intensiva de raças melhoradas para exportação de carnes. A meta é produzir commodities. Esses homens/ mulheres situados(as) nesta paisagem da agrotech se aproximam da classe política, se tornam políticos e às vezes ministros, demandam por constantes incentivos, privilégios em isenções e financiamentos, melhorias de infraestrutura. Na tipologia de Bassand (1990), são possuidores de uma identidade territorial de modernistas de consciência socioespacial capitalista.

\section{À guisa de conclusão}

Era de se esperar que, como Resbio, a proposta de gestão biorregional, numa mudança de escala nas estratégias de conservação da biodiversidade, trouxesse muitos benefícios para a conservação e melhor conhecimento do Cerrado.

Os aspectos favoráveis para a conservação do Cerrado seriam: a) a identificação e localização dos componentes-chaves dos ecossistemas: 
o que eles necessitam, como podem ser monitorados e manejados, e como explorá-los de modo sustentável (os mapeamentos das Figuras 1 e 2 são exemplos de ferramentas que instrumentalizam gestores e comunidades); b) os moradores e gestores poderiam repensar as suas atividades relacionadas à exploração dos recursos naturais, ao uso de terra e águas que, a despeito de estarem na Resbio, tornam-se escassos e mesmo ausentes; c) as identidades territoriais tencionam na Reserva e deveriam sistematicamente ser examinadas em seus conflitos.

Por fim, para Barbosa (2008), as comunidades e órgãos encarregados de manejo poderiam começar a ter cuidado com as ligações e interdependências entre os recursos e serviços ambientais de seus ecossistemas, com seu trabalho, com o fornecimento de alimentos e o suprimento de necessidades materiais, assim como o potencial e limites dos seus habitats.

Na medida do possível procurou-se elaborar uma construção que possibilitasse evidenciar um desmatamento do Cerrado histórico, signos de atopia e signos de degradação empobrecedores do valor da Resbio para a conservação ambiental e sustentabilidade.

Ademais, conclui-se que, a priori, já está bastante evidente uma identidade de vulnerabilidade, tendo em vista o signo de identidade frágil e a escassa intensidade informativa, pelas razões apresentadas ao longo do texto. Afirma-se, ainda, que a Reserva da Biosfera do Cerrado - Resbio Goyaz -, vinte e cinco anos após a criação, ainda carece de procedimentos eficientes para sua implementação. Faltam-lhe políticas eficazes. As paisagens culturais são dinâmicas e sua historicidade sinaliza a precarização da Resbio Goyaz, na contramão do concebido pela Unesco.

\section{Notas}

1 Os ruralistas constituem um grupo parlamentar de pressão muito importante no Congresso Nacional. Eles defendem os interesses do agronegócio e colocam em xeque as políticas sociais e ambientais do governo que possam restringir o acesso a terras (áreas protegidas e terras indígenas).

2 As Reservas da Biosfera, espalhadas hoje por 110 países, têm sua sustentação no programa "O Homem e a Biosfera" (MAB) da Unesco, desenvolvido com o Programa das Nações Unidas para o Meio Ambiente - PNUMA -, com a União Internacional para a Conservação da Natureza - UICN - e com agências internacionais de desenvolvimento. 


\section{Referências}

ALMEIDA, M. G. A captura do Cerrado e a precarização do território: um olhar sobre sujeitos excluídos. In: ALMEIDA, M. G. (Org.). Tantos cerrados. Goiânia: Vieira, 2005. p. 321-346.

ALMEIDA, M. G. Diversidades paisagísticas e identidades territoriais e culturais no Brasil sertanejo. In: ALMEIDA, M. G.; CHAVEIRO, E. F.; BRAGA, H. C. B. Geografia e cultura: os lugares da vida e a vida dos lugares. Goiânia: Vieira, 2008.

ALMEIDA, M. G. Território de Quilombolas: pelos vãos e serras dos Kalunga de Goiás: patrimônio e biodiversidade de sujeitos do Cerrado. Revista Ateliê Geográfico, ed. esp., v. 1, n. 9, p. 36-63, fev. 2010.

ALMEIDA, M. G. Fronteiras sociais e identidades no território do complexo da usina hidrelétrica da Serra da Mesa, Brasil. In: BARTHE-DELOIZY, F.; SERPA, A. (Org.). Visões do Brasil: estudos culturais em geografia. Salvador: EDUFBA; Edições L’Harmattan, 2012.

ALMEIDA, M. G.; VARGAS, M. A. M.; MENDES, G. F. Territórios, paisagens e representações: um diálogo em construção. Mercator, Fortaleza, v. 10, n. 22, p. 2335, jun. 2011.

BARBOSA, Á. G. As estratégias de conservação da biodiversidade na Chapada dos Veadeiros: conflitos e oportunidades. 2008. Dissertação (Mestrado em Desenvolvimento Sustentável) - Universidade de Brasília, Brasília, 2008.

BASSAND, M. Culture et régions d'Europe. Lausanne/Suiça: Presses Polytechniques et Universitaires Romandes, 1990.

BERINGUIER, C. Manières paysageres: première partie une méthode d'étude. GEODOC, Document de Recherche à 1,UFR Géographie et Amenagement, Université de Toulouse, n. 35, p. 2-58, 1991.

BRASIL. Ministério do Meio Ambiente. Portaria $n^{\circ}$ 275, de 5 de julho de 2018. Cria e define a composição do Conselho Deliberativo da Reserva da Biosfera do Cerrado, e dá outras providências. Diário Oficial [da] União, Brasília, n. 31, Seção 1, 10 jul. 2018, p. 91.

COPETA, C. La identidad: nueva categoria descriptiva del territorio y del paisaje. In: COPETA, C.; LOIS, R. (Ed.). Geografia, paisaje e identidad. Madrid: Editorial Biblioteca Nueva, 2009. p. 17-42.

COSGROVE, D. A geografia está em toda parte: cultura e simbolismo nas paisagens humanas. In: CORREA, R. L.; ROSENDAHL, Z. (Org.). Paisagem, tempo e cultura. Rio de Janeiro: Ed. Uerj, 1998. p. 84-122.

DOYLE, P. M. M. C. Reserva de Biosfera do Cerrado no Distrito Federal. Brasília: Instituto Brasília Ambiental, Governo do Distrito Federal, 2009. p. 15-23.

GANDY, M. Paisagem, estéticas e ideologia. In: CORREA, R. L.; ROSENDAHL, Z. (Org.). Paisagens, textos e identidade. Rio de Janeiro: Ed. Uerj, 2004. p. 75-90. 
IBGE - Instituto de Geografia e Estatística. Censo apropecuário 2017; Censo demográfico 2010. Disponível em: <https://www.ibge.gov.br/>. Acesso em: 27 abr. 2019.

NASCIMENTO, D. T. F.; SILVA, S. A. Dinâmica agropastoril em municípios do Nordeste Goiano perante a implantação da Reserva da Biosfera Goyaz. In: CONGRESSO IBERO-AMERICANO DE ESTUDOS TERRITORIAIS E AMBIENTAIS, 2014, São Paulo. Anais do CIETA, 2014. p. 3619-3638.

NASCIMENTO, D. T. F.; BRITO, B. N.; AVILA, R. C.; MELO, P. V. F. Caracterização socioeconômica e mapeamento físico como fomento à gestão e ao manejo da Reserva da Biosfera Goyaz, Goiás, Brasil. Geografia em Questão (Online), v. 9, p. 30-44, 2016.

PINTON, F.; AUBERTIN, C. Novas fronteiras e populações tradicionais: a construção de espaços de direitos. Ateliê Geográfico, Goiânia, v. 1, n. 2, p.1-26, dez. 2007.

SANTOS, M. A natureza do espaço: técnica e tempo-razão e emoção. 2. ed. São Paulo: Hucitec, 1997.

SAUER, C. O. A morfologia da paisagem. In: CORREAA, R. L.; ROSENDAHL, Z. (Org.). Paisagem, tempo e cultura. Rio de Janeiro: Ed. Uerj, 1998.

UNESCO. Reserves de Biosphère: notes téchniques. Paris: Unesco, 2008.

UNESCO. Mab: Política Nacional para as Reservas da Biosfera: o programa Homem e a Biosfera. Disponível em: < http://www.rbma.org.br/mab/unesco_02 politica.asp > Acesso em: 27 abr. 2019.

Maria Geralda de Almeida - Possui graduação em Geografia pela Universidade Federal de Minas Gerais, mestrado e doutorado em Geografia pela Université de Bordeaux III, pós doutorado em Geografia Humana pela Universidad de Barcelona, em Geografia Cultural pela Université Laval, Universita Degli Studi Di Genova e Universite de Paris IV Paris-Sorbonne. (iD https://orcid.org/0000-0002-4765-3354

Recebido para publicação em 8 de junho de 2019 Aceito para a publicação em 15 de julho de 2019 Publicado em 25 de julho de 2019 